Editorial

\title{
Disability requires rehabilitation and research: physiotherapist can act as prime mover
}

Volume 5 Issue 5 - 2016

\section{Editorial}

Disability is a curse for human life irrespective to race, ethnicity, class etc. Preventive measures are much more appreciated than curative one though disability is not completely curable but by appropriate rehabilitative measure we can return victim to near normal life and make him/her productive so that he/she can lead life independently rather than burden of the family and can contribute in national economy. Along with other parts of the world prevalence of disability in our country is in increasing trend. Different types of disable people we commonly observe in our daily life particularly in road side and majority of them are physically affected followed by blindness, deafness and mental retardation. But exact number of these disable people is scarce. Road traffic accident is a common picture and considered as one of the main reason of physical disability. Besides non communicable diseases especially stroke is in upward trend and resulting post stroke hemiplegia. But it is regret to say there are no rehabilitative services for this affected group. Multidisciplinary team approach is also quite absent. Only emergency medical management cannot resolve this problem; need long term complete rehabilitation. To achieve this engagement of physiotherapist, occupational therapist, speech and language therapist, orthotics, psychologist in Government hospital is crying need; demand of time to reduce distressful life of disable people. Child disability is another area we should focus. Cerebral palsy and autism is now very common word by dint of widespread dissemination of information by Government of Bangladesh but need depth research on these developmental disorders. Research institute funded by Government or donor agency can be instituted. Myth and superstition related to disability is still present particularly in rural area. School teacher, religious leader, community head can play vital role to remove fake idea about disability. Physiotherapists are dealing number of patients suffering physical disability namely hemiplegia and cerebral palsy in day to

\author{
Md Monoarul Haque,' Easmin Ara Doly² \\ 'Bangladesh Physiotherapy Association, Bangladesh \\ ${ }^{2}$ Firoza Bari Disabled Children Hospital, Chief Physiotherapist, \\ Bangladesh
}

Correspondence: Md Monoarul Haque, Publication Secretary, Bangladesh Physiotherapy Association, Bangladesh Email monoarmunna@yhoo.com

Received: August 24, 2016 | Published: September 12, 2016

day practice but it is difficult to bear treatment cost for poor people. Community based rehabilitation services can be promoted to touch marginalized people and hard to reach area. Firoza Bari Disabled Children Hospital is a nongovernment hospital providing both indoor and outdoor services for disable children with minimum cost but this type of hospital or facility should be available all over the country. According to Bangladesh Physiotherapy Association number of registered physiotherapists is around two thousand now. Policy maker can think about this skilled manpower and make them as a workforce in disability sector.

\section{Acknowledgments}

None.

\section{Conflicts of Interset}

None. 